\title{
IS 24 HOUR ECG MONITORING THE INVESTIGATION OF CHOICE TO DIAGNOSE PAROXYSMAL ATRIAL FIBRILLATION?
}

Dr. Thisarana Wijayaratne ${ }^{1}$, Dr. Purnima Jayasuriya ${ }^{1}$, Dr. Natalie Pettit ${ }^{1}$, Dr. Beniel Vincent ${ }^{1}$ ${ }^{1}$ Worcester Royal Hospital, Stroke Department, Worcester, United Kingdom.

\section{Introduction}

Atrial fibrillation (AF) is the most common sustained adult cardiac arrhythmia causing ischaemic strokes.

Paroxysmal AF (PAF) is undetected and untreated if sufficient ECG monitoring is not performed adequately.

Adequate diagnosis of AF following an ischaemic stroke is vital to prevent future strokes.

- Royal College of Physicians (RCP) stroke guidelines recommend a minimum of 24 hours ECG monitoring after a stroke to exclude PAF (1).

- We wanted to study if this recommendation is reliable in diagnosing PAF.

\section{Methods}

Retrospective study over a period of 6 months carried out in Worcester Royal Hospital, Worcestershire Acute Hospitals NHS Trust.

100 ischemic stroke patients without known AF underwent prolonged ECG monitoring (24-hr, 72-hr, 7 day).

Standards were set against the RCP stroke guidelines which recommend at least a 24hour ECG in all ischaemic stroke patients without known AF in order to diagnose PAF.

- Data was collected using patients electronic medical notes.

\section{Results}

Number of different tapes $(n=100)$ -

24 hour tapes- $97 \%$

72-hour tapes- $2 \%$

7 day tapes- $1 \%$

7-day tapes, $1 \%$

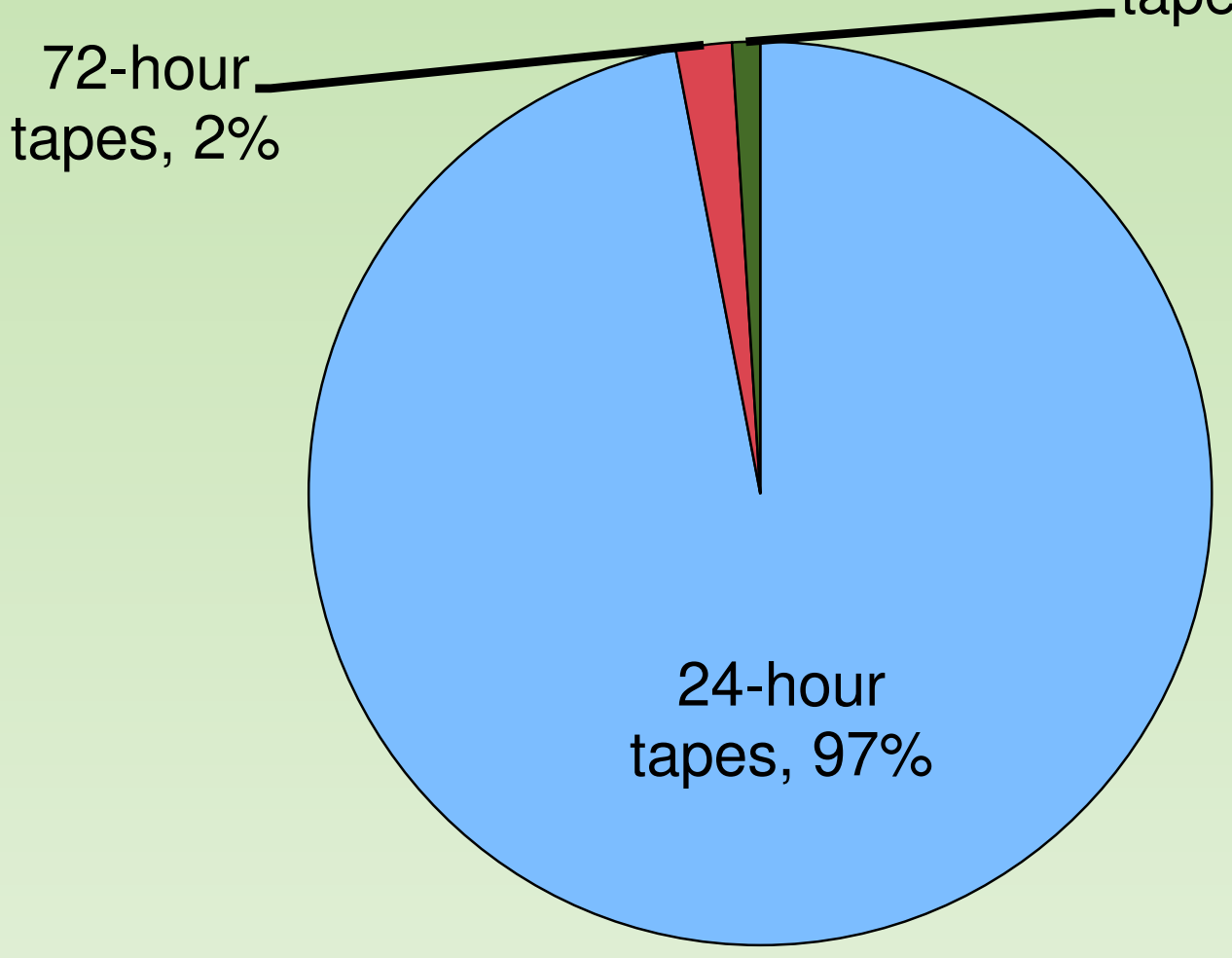

$\square$ 24-hour tapes $\square$ 72-hour tapes $\square$ 7-day tapes

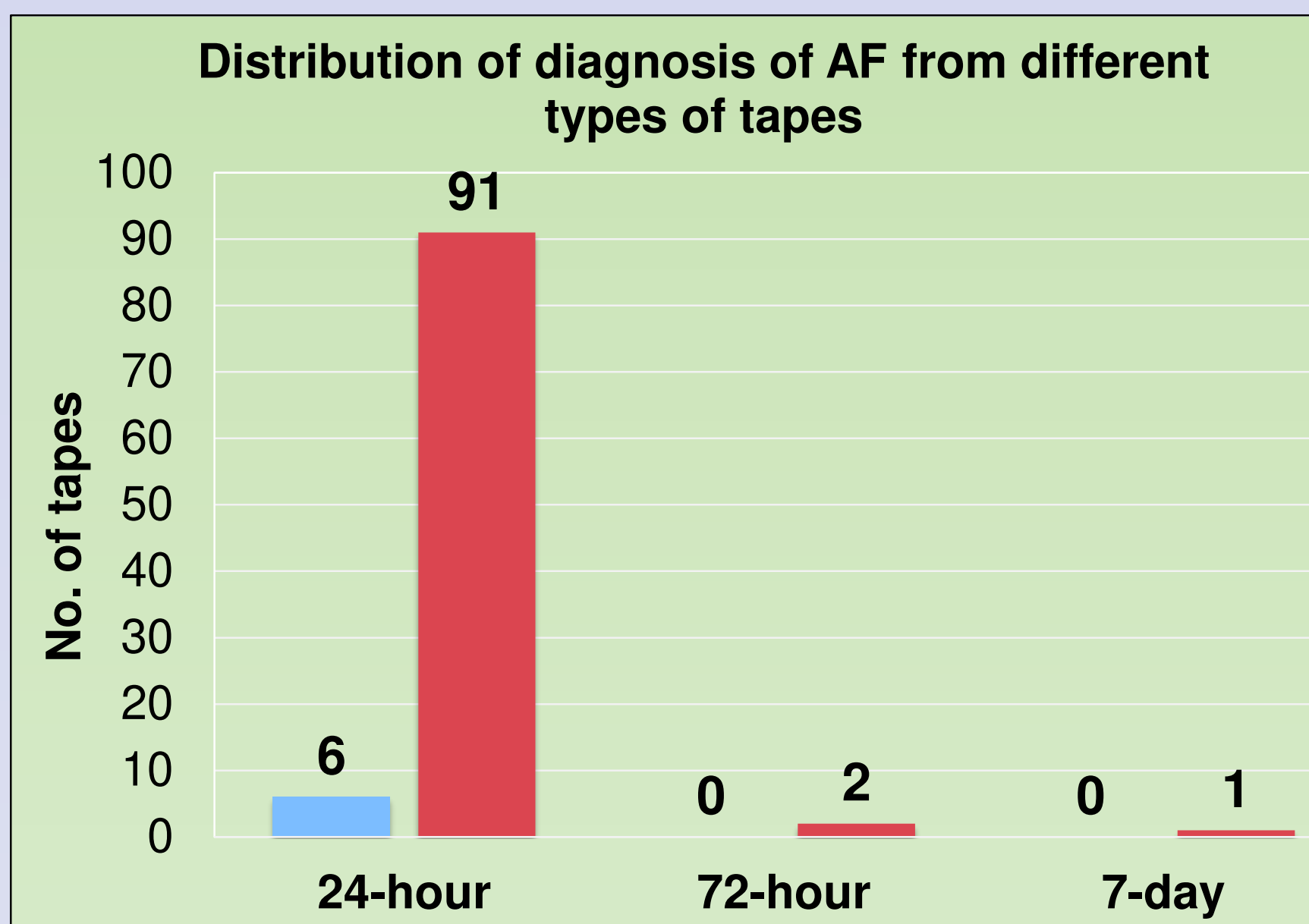

Type of ECG tape

Diagnosed with AF $\square$ Not Diagnosed with AF

*excluded

- Five 24-hour ECG tapes were done accidentally on patients with known AF of which two 24-hour tapes failed to identify AF.

- $\quad$ Three known AF patients detected on 24-hour ECG monitoring was excluded.

\section{Conclusion}

- Detection rate of AF on 24-hour ECG in our study was $6 \%$.

- In a systematic review involving 5038 subjects, the detection rate for new AF was 11.5\% (2).

- $\quad$ The two 24-hour tapes which failed to detect AF in known AF patients highlights the need for prolonged ECG monitoring.

- $\quad$ Overall, greater the period of ECG monitoring the greater the likelihood of diagnosing PAF.

\section{Limitations}

- Small patient population.

- $\quad$ There is limited data with regards to 72 hour tapes and 7 day tapes within this study. Prolonged ECG monitoring (>24 hours) will be required to diagnose patients with PAF.

\section{References}

1 Royal College of Physicians Stroke guidelines

(https://www.rcplondon.ac.uk/guidelines-policy/stroke-guidelines)

Accessed on- 09/05/2018

2 Kishore A, Vail A, Majid A, Dawson J, et al, 2014. Detection of atrial fibrillation after ischemic stroke or transient ischemic attack: a systematic review and meta-analysis. Stroke, 45, 520-6 